\title{
Hotfulla vuxna och maktgivande fantasier: makt, mognad och inre personskildring i två bilderböcker
}

\author{
Anna-Maija Koskimies-Hellman visar hur Michail Bachtins \\ karnevalsteori kan användas för att lyfta fram maktrelationerna \\ $i$ toå bilderböcker av Inger Edelfeldt respektive Tarja Lapintie. \\ Motsättningen barn - vuxna är det maktförhållande som blir centralt \\ både innehållsmässigt och strukturmässigt $i$ böckerna.
}

Två unga flickor rövas bort av ondskefulla vuxna gestalter. De förflyttas till ett annat land där de får nya liv som prinsessor. Ändå längtar flickorna tillbaka till sina vanliga liv, och med hjälp av en utomstående manlig karaktär lyckas de frigöra sig och återvända hem.

Handlingen i Inger Edelfeldts Genom den röda dörren, eller Sagan om den lilla flickan, Gråtkungen och Lejonpojken och Tarja Lapinties Kiveen kätketty linna ("Slottet i stenen"), båda från 1992, tycks inte i sammanfattad form bidra med någonting nytt till de barnlitterära konventionerna. Handlingsförloppet är starkt cykliskt, det farliga äventyret kompenseras med en trygg hemkomst, och kända folksagomotiv skymtar i bakgrunden. Ändå kan en närmare läsning lyfta fram komplexa frågor kring mognad, uppväxt och inre konflikter, då samspelet mellan ord och bilder inte låter böckerna reduceras till enkla, handlingsorienterade bilderböcker. Det finns ett djup i båda böckerna som döljer sig i karaktärsgestaltningen och de subtila nyanser som inte kan fångas enbart med ord men som lyfts fram av samspelet mellan visuellt och verbalt berättande.

I denna artikel jämför jag dessa två bilderböcker av Inger Edelfeldt och Tarja Lapintie. Jag analyserar de två unga flickorna som med hjälp av fantasins kraft bryter vardagens tristess och förflyttas från verkligheten till en ny värld. Jag undersöker fantasins maktgivande funktioner, men även de berättartekniska strategier som åskådliggör utvecklingen av huvudpersonernas maktpositioner. Karnevalsstrukturen och de skiftande maktpositionerna anser jag avspegla protagonisternas mognadsprocesser, och jag läser äventy- 
ren symboliskt som skildringar av flickornas inre världar. Således aktualiseras även frågan om huruvida det karnevalska äventyret används som ett grepp i den inre personskildringen. Berättelsernas yttre struktur är starkt konventionell, men gäller detta även för innehållet och karaktärsgestaltningen? Bryter böckerna mot den barnlitterära konvention som betraktar bilderböckerna som handlingsorienterade och bilderbokskaraktärerna som platta? Dessa är några av de frågor som jag ämnar besvara i denna artikel.

\section{Det maktgivande cykliska äventyret}

Michail Bachtins karnevalsteori åskådliggör litterära gestalters maktpositioner. Den medeltida karneval Bachtin undersöker kännetecknas av att hierarkin upphävs och maktpositionerna kullkastas (Bachtin 1986, 19 ff). I ett barnlitterärt sammanhang kan karnevalen användas till att illustrera en övergång från barndomens idyll till en viss mognad hos protagonisten och återvändandet till idyllen, en tidsfrist och ett smakprov på mognaden, så att säga (se bl. a. Stephens 1992, s. 126). Det cykliska mönstret är kännetecknande för barnlitteraturen och framhäver karnevalens tidsbegränsade natur (se: Edström 1980 och Nikolajeva 2000a samt Nodelman 1996, 155 f). Framför allt illustrerar den en förskjutning i maktpositioner, någonting som bilderböckerna i denna artikel kretsar kring.

Både Inger Edelfeldt och Tarja Lapintie skildrar kvinnliga protagonister och deras respektive tidsfrister i en annan värld. Utöver tidsfristen introduceras även andra karnevalska element $\mathrm{i}$ berättelsen. Den namnlösa huvudpersonen i Genom den röda dörren får sin tidsfrist när hon väntar på sin pappa som köper en tidning. En stor röd dörr öppnas i den gråa muren som flickan står bredvid, och dörren leder till ett övergivet tivoli. Karusellens röda häst leder flickan till det röda landet där hon möter Gråtkungen - en grå gestalt mitt bland de röda träden. Gråtkungen, vars gestalt förebådas av den bronsmask som finns ovanför den röda dörren (Nikolajeva 2000b, 236) och vars ansiktsdrag påminner om flickans pappa, rövar bort flickan till sitt slott och gör henne till en prinsessa. Flickan får leksaker och karameller och allt vad hon kan önska sig bara hon dansar för Gråtkungen - och hon dansar, trots att hon inte trivs, för annars dränker Gråtkungen hela världen i sina tårar. Flickans räddning blir lekkamraten Lejonpojken som vill att flickan ska fly, vilket hon till slut också vågar göra. När hon väl kommer ut genom den röda dörren har nästan ingen tid förflutit, men det har börjar regna - Gråtkungen har börjat gråta. 
Ett av kännetecknen för tidsfrist i fantasylitteratur är att den inte tar någon tid i primärhistorien (Nikolajeva 1988). I fantasivärlden kan en lång tid gå, men när huvudpersonen återvänder till verkligheten, verkar tiden där ha stått stilla under äventyret. Detta händer inte i den finska varianten av samma tema, Tarja Lapinties Kiveen kätketty linna, som till ytan annars följer ett liknande mönster som Genom den röda dörren. I Lapinties bok är det en fattig flicka, Sanni, som hör en sorglig sång i en sten - en drottning som önskar sig en liten flicka. Hon svarar på lockropet och förs av en liten skrynklig gubbe genom stenen till ett kungaslott där drottningen förtrollar henne så att hon inte längre kommer ihåg sin gamla identitet. Även Sanni lyckas till slut fly från slottet, men när hon återvänder till sitt hem, har modern blivit gråare då hon har väntat i flera månader.

Förutom denna tidsaspekt är likheterna böckerna emellan många. Även Sannis hemlängtan aktiveras av en pojke hon leker med i slottsparken. I båda böckerna har flickorna starka motpoler dels i Gråtkungen som hotar att dränka hela världen i sina tårar och dels $\mathrm{i}$ den ondskefulla drottningen som drogar ner Sanni varje natt. Gråtkungens hotfulla personlighet förstärks av den illustration där han sitter hopsjunken i sin mörka dräkt i sitt droppstensslott, rökande och gråtande - en stark kontrast till den lilla flickan som skildras som en genomskinlig älva i sin gula ballerinadräkt. Även drottningens mörka sidor förstärks av det visuella berättandet i Kiveen kätketty linna. Drottningens hår är flätat med små ormar och en hotfull svart korp sitter på hennes axel och äter chokladpraliner ur hennes hand. [IIl. 1] Gråtkungen framstår inte direkt som ondskefull - snarare är han djupt deprimerad och förmår inte låta flickan gå. Drottningen däremot gestaltas som en häxa och ormarna i hennes hår symboliserar det ondskefulla i hennes inre. Båda flickorna lever på ytan lyxigt, vilket framgår av illustrationerna som i båda böckerna skildrar ett överflöd av läckerheter och leksaker, men de vill befria sig från de starka, hotfulla gestalterna som fångat dem.

Vistelsen i den kungliga miljön är maktgivande, trots att flickorna inte trivs. De båda flickorna kan erbjuda det enda ljuset i livet för dem som tillfångatagit dem - och de har även makten att beröva dem det. I och med att de dessutom lyckas ta sig ut ur fångenskapen (visserligen med hjälp av Lejonpojken respektive den skrynkliga lilla gubben), framstår de nästan som hjältar i slutet av berättelserna.

\section{Ambivalens i visuellt och verbalt berättande}

Hur borde dessa två kungliga världar tolkas? Frammanar ikono- 


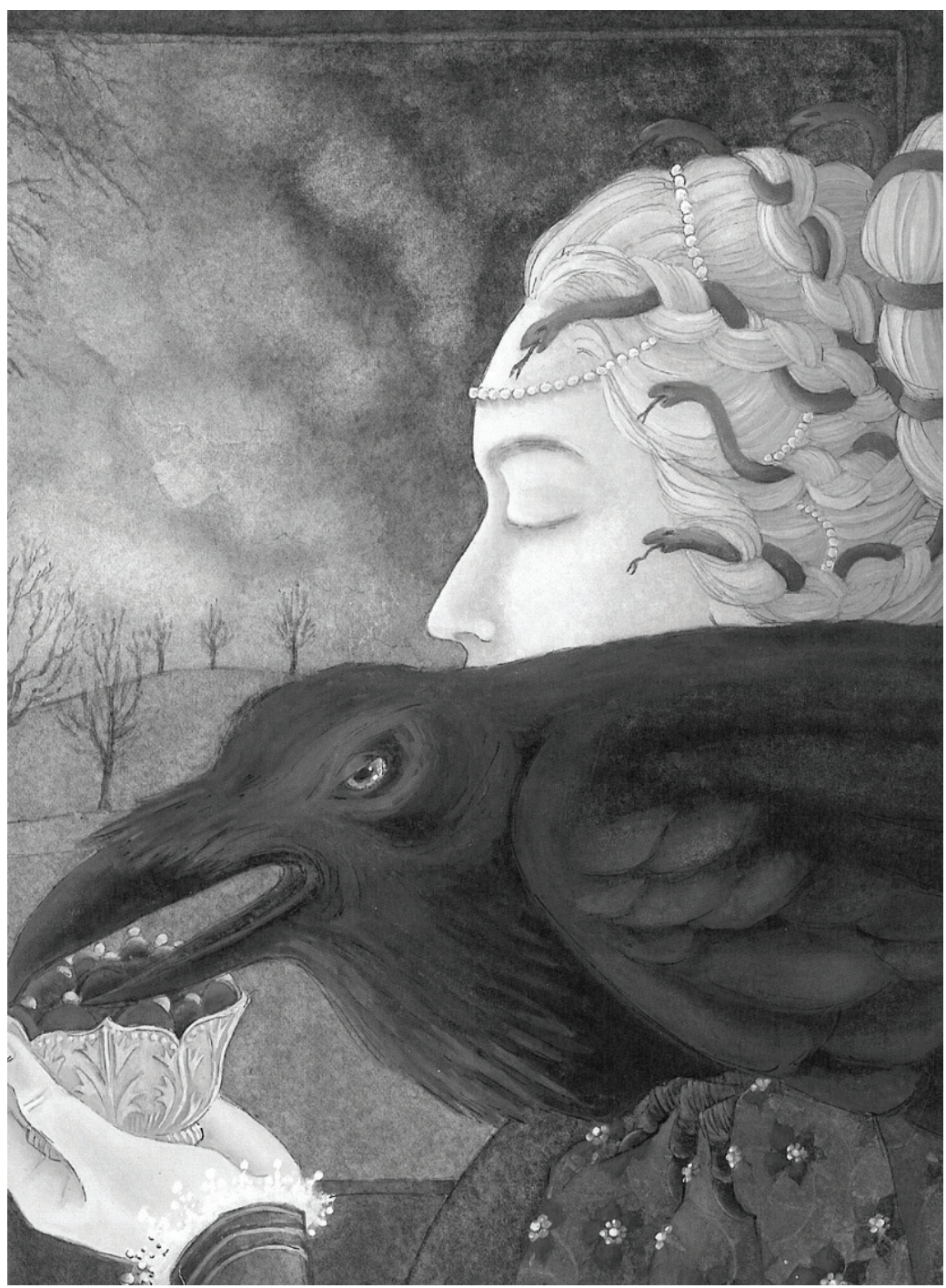

III. I. Kiveen kätketty linna (Slottet i stenen) av Tarja Lapintie. Helsingfors:Tammi, I992

texten en mimetisk läsning eller pekar den på en symbolisk nivå där händelserna betraktas som representationer av flickornas inre landskap? Genom den röda dörren försätter läsaren i tvekan angående äventyrets natur i och med att illustrationerna är symboliskt laddade. Jag nämnde redan att flickans pappa har flera likheter med Gråtkungen. Dessutom finns det visuella detaljer som ifrågasätter en eventuell mimetisk läsning: i det övergivna tivolit finns en vagn där dockteater har spelats. Det finns tre dockor på scenen som alla liknar 


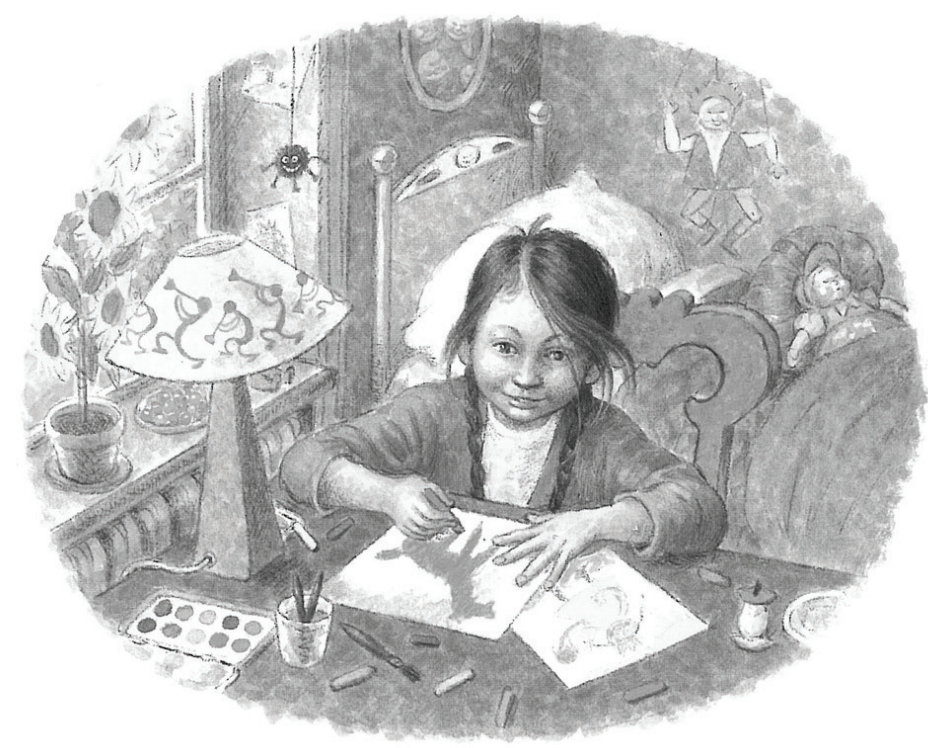

III. 2. Genom den röda dörren, eller sagan om den lilla flickan, Gråtkungen och Lejonpojken, text och illustration Inger Edelfeldt. Stockholm: Bonniers Juniorförlag, 1992

de tre titelpersonerna i berättelsen. Dockan Gråtkungen ligger livlös över scenkanten medan dockorna som föreställer den lilla flickan och Lejonpojken ser trotsiga ut. Dockan Lejonpojken dyker upp igen på berättelsens sista uppslag som en marionett i flickans rum - där hon dessutom tecknar en röd häst och en prinsessa i gul klänning. Den fråga som uppstår är om tivolit och dockteatern är verkliga eller om de ingår i flickans fantasi. Var börjar hennes fantasi och var slutar den? Är den röda dörren och allting som finns bakom den flickans inre värld, eller finns de i verkligheten?

Varken den visuella eller den verbala berättelsen stöder direkt den tolkning att dörren och tivolit skulle vara verkliga. Den verbala berättaren är förvånad när dörren dyker upp i början av berättelsen: "Men vad nu! I muren är det en röd dörr! Den fanns inte där förut!" (Edelfeldt 1992, 3) Den visuella berättaren låter däremot dörren försiktigt tyna bort på det sista uppslaget. Allting bortom stadsmuren ter sig som flickans egen fantasi som inspirerats av den gråa muren, det duggregniga vädret, hennes egen pappa och möjligen inredningen $\mathrm{i}$ hennes sovrum.

Den fråga som återstår är hur den inre värld som berättelsen förmedlar ska tolkas. Maria Nikolajeva gör en tolkning utifrån färgtemat $\mathrm{i}$ berättelsen och lyfter fram den röda färgens betydelse. Hon menar att färgen symboliserar kvinnan och att hela berättelsen kan läsas som en skildring av den kvinnliga huvudpersonens befrielse 
från en dominerande far-dotter-relation (Nikolajeva 2000b, 236 f). Som motpol till den dominerande fadern (representerad av den utpressande Gråtkungen) nämner Nikolajeva "en ung manlig partner", Lejonpojken (Nikolajeva 2000b, 237). Jag finner dock inte denna läsning av Genom den röda dörren som en ung kvinnas önskedröm helt tillfredsställande. Den visuella berättaren skildrar huvudpersonen som en liten flicka, medan den av Nikolajeva presenterade önskedrömmen med menstruationssymbolik snarare förknippas med en ung kvinna. Jag anser att denna tolkning står i kontrast mot den visuella framställningen av den namnlösa huvudpersonen i Genom den röda dörren. Hon skildras tydligt som ett barn som leker med dockor och tecknar med färgkritor. [Ill. 2]

Naturligtvis kan man inte ignorera färgsymboliken, de lockande frukterna som ropar "Ät mig! Ät mig!" (Edelfeldt 1992, 10, författarens kursiv), de två manliga gestalterna och kopplingarna till flickans fiktiva verklighet, men att entydigt deklarera berättelsen som en symbolisk skildring av en ung kvinnas relation till sin dominerande fader är tveksamt. I boken framställs snarare en ensam flicka som använder den tråkiga väntetiden till att fantisera fram ett äventyr där hon blir en prinsessa som lyckas ta sig loss från den farliga Gråtkungens slott, vilket får henne att känna sig som en hjälte efter att fantasin är avslutad. Fantasin inspireras av hennes omgivning och eventuellt även av hennes tidigare bekantskap med folksagor.

Framställningen av det inre landskapet - ifall det ska tolkas som ett sådant - i Kiveen kätketty linna skiljer sig något från den i Genom den röda dörren. Jag nämnde redan den avvikande tidsframställningen - något som förknippar berättelsen starkare med intertexten folksagan än den fantastiska berättelse som Genom den röda dörren med vissa reservationer kan sägas representera. Stöd för tolkningen av kungaslottet som Sannis inre landskap fås av att hon sitter i skogen och lyssnar på stenen som sjunger. Sannis fattiga bakgrund gör att hon inte har annat att leka med än skogen och dess djur, och det verkar som om hon var van vid att fylla ut tristessen med livliga fantasier. Hon föreställer sig en kunglig bal, kvinnor i vackra klänningar, och denna mentala bild skildras av den visuella berättaren som genomskinliga figurer som dansar bland träden i skogen. Där är det alldeles klart att det är fråga om Sannis fantasi och ingenting annat. På det följande uppslaget, som föreställer våren ett år senare, sitter hon på en blomsteräng (ett intervisuellt samband till den inledande scenen i Tove Janssons Den farliga resan, 1977), hör stenens sång igen och låter sig lockas av den. Den lilla skrynkliga gubben som leder Sanni till slottet skildras aldrig i bild, och på det uppslag som skildrar 
övergången från verkligheten till vad jag tolkar som hennes fantasi är den visuella berättaren mycket sparsam i sitt berättande. Övergången skildras överhuvudtaget inte i bild, däremot skymtar vita liljor i det övre vänstra hörnet och en kudde med en gyllene krona i det nedre högra hörnet. På det därpå följande ordlösa uppslaget är den nya kungliga familjen redan klädd i festkläder och följer narrarnas skådespel - vilket utgör ett tydligt samband med karnevalen - framför ett dignande middagsbord.

Fantasin är maktgivande för en fattig flicka som Sanni. Att leva bland guld och glitter och ha tillgång till all världens delikatesser tillsammans med den världsliga makt som hon som prinsessa har, måste vara den totala motsatsen till vad hon upplevt fram till dess. En sådan fantasi är säkert tillfredsställande under en kortare tid, men i och med att det inte är fråga om att Sanni skulle vilja bryta med sin riktiga mamma (hon är knappast ens gammal nog för att göra det), kan inte karnevalen pågå i all oändlighet. Därför behövs en ondskefull drottning - en ond styvmor, om man vill läsa henne som en variant av det motivet - som ger flickan en anledning att återvända till sitt hem.

Tidsaspekten och den symmetriskt indikativa modalitet som antyder att händelserna verkligen ägt rum, står inte helt i samklang med denna läsning. Den verbala berättaren är opersonlig och använder en vuxen röst som visserligen fokaliserar Sanni men skapar ett starkt intryck av distans. Distansen förstärks genom att både texten och bilderna är brett inramade. Den visuella berättaren är allvetande och visar bland annat drottningens mörka sida i den tidigare nämnda illustrationen och slottets övergivna fasad ur en synvinkel som ter sig mera objektiv än de illustrationer som fokaliserar Sanni. Den verbala berättelsen avslutas med stenens sång: "Så här avslutas / sagan om den gyllene solens land. / Den slutar som sagor brukar: / Bekymren är borta / och de lever lyckliga i alla sina dagar." (Lapintie 1992, 31, min översättning). Den verbala berättaren betonar att det är fråga om en saga - men det som förblir oklart är vilken del av detta som ska uppfattas som en saga. Händelserna i slottet? Eller hela berättelsen? I så fall har väl inte stenen kunskap om att den också befinner sig $\mathrm{i}$ en saga? Med alla dessa frågor i bagaget är det svårt att acceptera den symmetriskt indikativa, konstaterande, tonen som ikonotexten $\mathrm{i}$ princip har berättelsen igenom. Den symboliska framställningen av händelserna som ett tillfälligt avbrott ur fattigdomen och ensamheten tränger sig på den mimetiska läsningen.

Förutom den ovannämnda sången, ifrågasätter varken texten eller bilderna varandra och båda framställer händelserna som sanna. 
Såväl den visuella som den verbala berättaren förespråkar en mimetisk läsning: händelserna har ägt rum i den fiktiva verkligheten. Denna läsning stöds även av den visuella berättarens framförda faktum att Sannis hår har vuxit betydligt under äventyrets gång. En visuell detalj som däremot ifrågasätter den mimetiska läsningen är den vita liljan som förekommer både i den kungliga miljön och i Sannis fattiga hem. Jag nämnde redan att det uppslag som ersätter skildringen av övergången från verklighet till fantasi innehåller vita liljor i det övre vänstra hörnet, men liljan upprepas i bild gång på gång. Den kungliga festsalen är dekorerad med vita liljor, men så är även Sannis sovrum på det sista uppslaget. I hemkomstscenen springer Sanni hemåt med en vit lilja i handen, och det är förmodligen denna samma lilja som pryder sovrummet. Har Sanni hämtat liljan med sig från slottet eller har hon aldrig ens varit i slottet? Kanske har hon bara suttit på blomsterängen och fantiserat på samma sätt som flickan som väntar på sin pappa i Edelfeldts bok. Från blomsterängen kan hon ha plockat med sig en blomma som hon ger till sin mamma. Eller kanske är allt detta en lek - mamman är med och leker att flickan rövas bort och är lycklig, precis som den vilda bebins mamma i Barbro Lindgrens och Eva Erikssons Den vilda bebiresan (1982), när barnet kommer hem från sin låtsasresa. Ingen av läsningarna är helt övertygande, men som i de flesta ambivalenta bilderböckerna, är det spänningen mellan de olika läsningarna som skapar den dynamik som krävs för att behålla läsarens intresse.

\section{Inre processer antyds}

Trots en viss ambivalens i framställningen, anser jag att tidsfristmotivet tydligt kommer till uttryck i både Genom den röda dörren och Kiveen kätketty linna. De gestaltar, med några reservationer, en karneval, då de erbjuder en konkret statushöjning för barnprotagonisterna. Tidsfristens typ fungerar även som ett grepp i persongestaltningen. Att fantisera om att bli tillfångatagen och förvandlad till en prinsessa med obegränsad tillgång till läckerheter och rikedomar ter sig som en naiv önskan som kan ha sitt ursprung i folksagor. På den nivån framstår inte protagonisterna som särskilt komplexa personer. En närmare undersökning av det icke-verbala innehållet $\mathrm{i}$ fantasierna kan dock ändra på den uppfattningen. Maria Nikolajeva visar hur färgerna i Genom den röda dörren kan användas som underlag till en psykoanalytisk tolkning (en tolkning som jag visserligen inte anser vara helt övertygande), och även i Kiveen kätketty linna finns det element som i den freudianska psykoanalysen 
är betydelsebärande: Det enkla huset och dess variant, slottet, står för människan i sin helhet (Freud 1996, 146). Den enkla, till sin fasad släta, stugan står i kontrast mot det utsmyckade slottet, och kontrasten framhäver Sannis övergång i den kvinnliga sfären (Freud 1996, 149). Även blommor är kvinnliga fallossymboler (Freud 1996, 151), och den vita liljans betydelse för handlingen har redan klargjorts. Mat i form av godsaker symboliserar sexuell njutning, och genom frukt symboliseras den kvinnliga kroppen (Freud 1996, 149 f). Även de underjordiska grottorna och tunnlarna som protagonisten rymmer genom kan associeras dels med den kvinnliga kroppen och dels med det undermedvetna, i form av husets, slottets, understa våning (Freud 1996, 149).

En undermedveten kamp mellan barndom och mognad, oskuldsfullhet och sexualitet kan således vara en av de symboliska nivåerna även i Kiveen kätketty linna. I den mest uppenbara maktkampen mellan barn och vuxna är även tillfångatagarnas kön av betydelse. De ondskefulla eller elaka vuxna har sina goda motparter i de föräldrar som väntar på huvudpersonerna utanför fantasivärlden, och ett samband till folksagomotivet "den onda styvmodern" (se bl. a. Bettelheim 1982, 231 ff) kan anas i berättelserna. Gråtkungen och den ondskefulla drottningen kan sägas personifiera den namnlösa flickans pappas respektive Sannis mammas skuggsidor i flickornas fantasier. Kiveen kätketty linna kan således skildra ett komplext mor-dotter-förhållande, medan Genom den röda dörren gestaltar förhållandet mellan far och dotter, som Maria Nikolajeva föreslår. Förhållandet mellan protagonisten och hennes fader kännetecknas enligt Nikolajeva av faderns dominans. I Genom den röda dörren kan det även vara fråga om ett oidipus-komplex. Oavsett vilken analytisk modell som tillämpas på protagonisterna i Kiveen kätketty linna och Genom den röda dörren, inbjuder båda böckerna till djupa psykologiska spekulationer och visar således att karaktärernas personligheter tillägnats utrymme i ikonotexten. De icke-verbala, och möjligen även omedvetna, inre tillstånden kommer till uttryck genom fantasierna - som är ambivalenta i sin framställning.

\section{Slutsatser}

Ambivalensen i Genom den röda dörren skapas med hjälp av små visuella detaljer: dockan ifrågasätter det mimetiska äventyret och förespråkar en symbolisk tolkning, medan Kiveen kätketty linna ifrågasätter den symboliska tolkningen av ikonotexten genom att dels frammana en mimetisk läsning på grund av tidsflödet och dels låta 
den verbala berättaren, genom den talande stenen, undergräva verkligheten.

Karnevalsstrukturen lyfter således fram de två flickprotagonisternas mognadsprocesser, steg mot det okända men med trygg hemkomst. Det cirkulära mönstret knyter flickorna starkt vid barndomen och berättelserna vid den barnlitterära konventionen. Nyfikenheten på världen utanför idyllen fungerar dock här som det centrala och betydelsebärande motivet.

Analysen av dessa två bilderböcker aktualiserar även en diskussion kring makt och maktpositioner. Karnevalsstrukturen fäster uppmärksamheten vid äventyrens maktgivande funktion, men även en annan aspekt av makt framträder. Motsättningen barn - vuxna är det maktförhållande som blir centralt i båda böckerna, både innehållsmässigt och strukturmässigt. Både hotet och tryggheten förkroppsligas hos vuxna personer såväl hos Edelfeldt som hos Lapintie. De goda föräldrarnas skuggsidor personifieras av tillfångatagarna. Trots att fantasierna är maktgivande för protagonisterna, befrias de inte från sina underlägsna positioner som barn efter äventyrets slut. I det avseendet är båda böckerna bundna vid traditionen.

Trots den konventionellt cirkulära formen, följer Edelfeldt och Lapintie inte konventionerna i sina karaktärsskildringar. Med hjälp av fantasierna skapas nyanserade och intressanta karaktärer, och samtidigt visas att bilderboken är ett ypperligt medium för skildringar av komplexa karaktärer och deras inre tillstånd.

${ }^{1}$ Här finns ett intertextuellt samband till det kvinnliga monstret Medusa i grekisk mytologi. Medusas hår bestod av ormar och alla som såg henne $\mathrm{i}$ ögonen förvandlades till sten. Även den svarta korpen är olycksbådande och kopplas ofta samman med det ondskefulla i folktraditionen (Larousse dictionary of world folklore, 365).

\section{Bibliografi}

Bachtin, Michail. Rabelais och skrattets historia (Tvortjestvo Fransua Rable $i$ narodnaja kultura srednevekovja i Renessansa,1965), Uddevalla: Anthropos, 1986.

Bettelheim, Bruno. Sagans förtrollade värld: folksagornas innebörd och betydelse (The uses of enchantment: The meaning and importance of fairy tales, 1976), Stockholm: Norstedt, 1989.

Edelfeldt, Inger. Genom den röda dörren, eller Sagan om den lilla flickan, Gråtkungen och Lejonpojken, Stockholm: Bonniers Juniorförlag, 1992. 
Edström, Vivi. Barnbokens form: en studie i konsten att berätta, Göteborg: Stegelands, 1980.

Freud, Sigmund. Orientering i psykoanalysen (Vorlesungen zur Einführung in die Psychoanalyse, 1915-17), Stockholm: Natur och kultur, 1996.

Jansson, Tove. Den farliga resan, Helsingfors: Schildts, 1977.

Lapintie, Tarja. Kiveen kätketty linna, Helsingfors: Tammi, 1992.

Larousse dictionary of world folklore, red. Alison Jones, Edinburgh: Larousse, 1995.

Lindgren, Barbro och Eva Eriksson. Den vilda bebiresan, Stockholm: Rabén \& Sjögren, 1982.

Nikolajeva, Maria. The magic code: the use of magical patterns in fantasy for children, diss. Stockholm: Almqvist \& Wiksell, 1988.

Nikolajeva, Maria. From mythic to linear: time in children's literature, Lanham, Md.: Scarecrow Press, 2000 (2000a).

Nikolajeva, Maria. Bilderbokens pusselbitar, Lund: Studentlitteratur, 2000 (2000b).

Nodelman, Perry. The pleasures of children's literature, 2. utg., New York: Longman, 1996.

Stephens, John. Language and Ideology in Children's Fiction, London: Longman, 1992. 